\title{
Para "Além do Zênite": um estudo de três poemas de Roça barroca, de Josely Vianna Baptista
}

Maria Salete Borba ${ }^{l}$

\begin{abstract}
The purpose of this article is to read how certain traces of Baroque are presented in three poems of the second part of Roça barroca, by the Brazilian poet, essayist and translator Josely Vianna Baptista (2011). Baptista claims to read the past with the present to give it visibility, coexistence and respect for the word. Therefore, an anachronistic method is necessary as a Baroque reading procedure. This method is sometimes presented by the political-poetic bias, or by the bias of the word-image, and contributes to rethinking the present with the past. For this reason, the theoretical reference of this analysis includes, on one hand, the studies on anachronism coming from the researches on image that we can read in Georges Didi-Huberman (2013), as well as the studies on Baroque by Walter Benjamin (1984); on the other hand, Haroldo de Campo's (1969) considerations on visual and verbal collages by Kurt Schwitters are also important. The reading of this surviving Baroque will be the device, as said by Giorgio Agamben (2005), to think, to discuss some characteristics that still are present in contemporaneity, especially in the poetic| political work of Josely Vianna Baptista.
\end{abstract}

Keywords: Josely Vianna Baptista; baroque; Brazilian contemporary poetry.

Resumo: O objetivo deste artigo é ler três poemas da segunda parte do livro Roça barroca da poeta, ensaísta e tradutora brasileira Josely Vianna Baptista (2011). Nesta leitura dos poemas de Baptista apresenta-se a importância de se ler o passado com o presente, para dar visibilidade às sutilezas dos poemas que nos revelam a convivência de saberes diversos e o respeito à palavra. Portanto, para ler seus poemas partiu-se de um método anacrônico como procedimento de leitura do Barroco. Tal método permitiu ora ler o viés político-poético do poema, ora, o viés da palavra-imagem, e, além disso, contribuiu para se repensar como o presente está impregnado dos traços do passado. Por isso, o referencial teórico desta análise inclui, por um lado, os estudos sobre o anacronismo advindos das pesquisas sobre a imagem que podemos ler em Georges Didi-Huberman (2015), assim como, dos estudos sobre o Barroco de Walter Benjamin (1984); por outro lado, as considerações sobre as collages visuais e verbais de Kurt Schwitters, realizadas por Haroldo de Campos (1969) também contribuem para a presente análise. A leitura desse Barroco sobrevivente será o dispositivo, como diria Giorgio Agamben (2005), para se pensar e discutir quais as características do Barroco que ainda se fazem presentes na contemporanei-

1 Professora Adjunta B de Literatura Brasileira do Departamento e da Pós-graduação em Letras da Universidade Estadual do Centro-Oeste. 
dade, em especial no trabalho poético/político de Josely Vianna Baptista. Palavras-chave: Josely Vianna Baptista; barroco; poesia brasileira contemporânea.

Introdução

O tempo feliz é o dos longos sóis eternos, em que os seres são homens e são deuses.

Pajé guarani

Sempre, diante da imagem, estamos diante do tempo.

Georges Didi-Huberman

Em Diante do tempo. História da arte e anacronismo das imagens, Georges Didi-Huberman (2015) traz para a discussão a necessidade de uma reconfiguração da história e do tempo. Já no texto de abertura "A história da arte como disciplina anacrônica", o historiador e filósofo francês, pelo título, reivindica uma releitura da história, em especial, da história da arte. Esse primeiro texto é dividido em cinco fragmentos que auxiliam, por um lado, a leitura e o entendimento do conceito anacronismo, e, por outro lado, evidenciam a importância da ruptura e da montagem; ou seja, a necessidade de se trazer à tona a dinâmica das diversas temporalidades que constituem a história e, também, a litertura.

O anacronismo seria, assim, numa primeira aproximação, um modo temporal de exprimir a primeira aproximação, um modo temporal de exprimir a exuberância, a complexidade, a sobredeterminação das imagens. (DIDI-HUBERMAN, 2015, p. 22)

Partido desse entendimento, a presente análise tem como foco de estudo a leitura de três dos trinta poemas de Roça barroca (2011), da poeta paranaense Josely Vianna Baptista (1957-) $)^{3}$, leitora/tradutora de Lezama Lima, Jorge Luis Borges, Alan Pauls, Mario Bellatin e Severo Sarduy.

Os ensinamentos de Walter Benjamin (1984) e de Georges Didi-Huberman (2015) contribuem enquanto fio condutor da análise e reflexão sobre a palavra fantasmática e insistente, que advém dos cantos dos Mbyá-Guarani, que continuam a se fazer presente mesmo em sua ausência. Esse desdobramento da palavra como algo inapreessível, como o eco, como o ar, é uma das características advindas do pensamento moderno que, em sua retomada, inclui traços de um barroco exuberante e rico.

Baptista (2011) em Roça barroca reúne, no mesmo volume de uma edição bilíngue

2 Este artigo faz parte dos resultados do pós-doutorado realizado na Universidade de Leiden sob a supervisão da professora Dr. Nanne Timmer.

3 Além do reconhecido trabalho como tradutora/leitora, é autora dos livros Ar (1991), Corpografia (1992), A concha das mil coisas maravilhosas do velho caramujo (2000), O outro (2001) em parceria com Arnaldo Antunes, Sol sobre nuvens (2007) e Roça barroca (2011). Como é de conhecimento público, foi com o apoio de uma Bolsa Vitae de Artes que a escritora realizou em 2002 o projeto "Do zero ao zênite", o que resultou no conjunto de poemas intitulado Moradas nômades, que faz parte do livro Roça barroca (2011), e no manuscrito "A fonte da fala". 
(guarani/português), três cantos traduzidos da tradição guarani que falam sobre o mito da criação do mundo Mbyá-guarani do Guairá e uma série de poemas que a poeta chamou de Moradas nômades. Lemos Moradas nômades como o resultado de um diálogo com os cantos dos Mbyá-guarani. Ou seja, Josely Vianna Baptista ao nos apresentar os cantos em sua versão original e na tradução, aproxima-nos de um passado em que a palavra é o instrumento mais valioso.

No texto de abertura de Roça barroca, "Nota da autora sobre as palavras azuis celestes", a ensaísta/poeta/tradutora comenta que os cantos do Ayvu rapyta é "[u]ma das manifestações mais importantes da mitopoética ameríndia" (BAPTISTA, 2011, p. 9); também destaca que tais cantos foram coletados pelo antropólogo paraguaio León Cadogan em 1940 e, posteriormente, traduzidos ao espanhol e publicados no volume chamado Ayvu rapyta: Textos míticos de los Mbyá-Guarani del Guairá. Sobre León Cadogan, um detalhe importante nos é revelado no texto de apresentação de Augusto Roa Bastos que faz parte de Roça barroca, chamado "Catecismo da beleza"; nele o escritor paraguaio nos narra o motivo pelo qual apenas em 1940, esses cantos míticos dessa etnia são revelados. Conforme Roa Bastos,

[n]ão sabemos há quanto tempo andavam vagando pela língua os cantos do Ayvu rapyta antes que León Cadogan os recebesse como testemunho da gratidão dos Mbyá do Guairá. Ao salvar o indígena Mario Higinio de uma condenação injusta na prisão de Villarrica, Cadogan ganhou a confiança do cacique Pablo Vera, de Yro'ysã, que decidiu revelar-lhe os textos sagrados que eram mantidos cuidadosamente guardados de toda intrusão estrangeira (ROA BASTOS, 2011, p.17-18).

Roa Bastos, como um bom narrador, continua seu texto imaginando, detalhando como deve ter sido o momento solene da revelação dessas "primeiras belas palavras".

Numa serena luz crepuscular, reunidos em volta de uma fogueira, León Cadogan talvez tenha sido o primeiro homem branco que conheceu as profundezas das primeiras belas palavras ou ñe'e ayvu porã tenonde (ROA BASTOS, 2011, p. 18, grifo do autor).

O que lemos nesses breves fragmentos do texto de Augusto Roa Bastos confirma o que nos relatam as palavras de outro antropólogo, Bartomeu Melià, que servem de epígrafe ao texto introdutório de Josely Vianna Baptista.

A palavra é efetivamente para o Mbyá o objeto e o sujeito de sua arte, seu conteúdo, sua forma. O definitivo de sua essência, de seu modo de ser, é a palavra, e toda a sua vida se estrutura para ser fundamento e suporte de palavras verdadeiras. Desde a criação do mundo e do homem, que é vista como criação da palavra, até a morte de cada pessoa, que é valorizada como grau maior ou menor de palavra realizada, o Mbyá só se entende a si mesmo em função da palavra. (MELIÀ apud BAPTISTA, 2011, p. 9, grifo do autor).

Portanto, a primeira parte de Roça barroca é composta pela tradução dos três primeiros capítulos do livro Ayvu rapyta: Textos míticos de los Mbyá-Guarani del Guairá, de León Cadogan (1992), que contêm, segundo a tradutora, alguns dos principais conceitos da cosmologia guarani. Os três primeiros cantos guarani que Josely nos apresenta são: 1. Maino i reko ypykue: "Os primitivos ritos do Colibri", que descreve a cena da criação 
do universo Mbyá-Guarani:

[...] nos últimos confins do caos obscuro em que Ñande Ru Papa tenonde-o deus supremo - foi de si mesmo se desdobrando e se abrindo feito flor [...] em seu desabrochar o deus se entrevê no escuro, iluminado pelo "sol" de seu próprio coração. O Colibri, em adejos sobre a fronte do deus, farta de flores, respinga água em sua boca e o alimenta com frutos do paraíso (BAPTISTA, 2011, p. 10-11).

2. Ayvu rapyta: "A fonte da fala". Josely Vianna Baptista ao descrever literalmente o canto, nos apresenta o aparecimento da palavra-alma, ou seja, a palavra como algo sagrado.

Neste canto o deus supremo vai desdobrando de si o fulgor do fogo e a neblina que dá vida, a fonte do amor e do som sagrado. Faz a fonte da fala aflorar de si e fluir por seu corpo, tornando-a sagrada, palavra-alma de origem divina (BAPTISTA, 2011, p. 11).

3. Yvy tenode: "A primeira terra". Neste último canto somos colocados diante do deus supremo, aquele que faz surgir a Terra da ponta de seu bastão, tal como podemos ler na transcrição abaixo.

Com seu saber contido em seu ser-de-céu e sob o sol de seu lume criador, ou seja, com sua sabedoria e seu poder, o deus supremo faz surgir da ponta de seu bastão a Terra, criando em seguida os sete céus, ou firmamentos e suas escoras, as pindovy, palmeiras azuis-indestrutíveis, eternas, milagrosas. Surgem os primeiros animais. Antes de recolher-se em seu profundo paraíso, o deus supremo pede aos "pais e mães verdadeiros" que nomeiem seus filhos como numes protetores das fileiras de labaredas, da neblina que engendra as palavras inspiradas, da chuva e do granizo, fontes de frescor, para que sua sorte prospere favoravelmente, para que entre eles impere a temperança, e para que orientem sua existência com normas próprias de conduta. Por fim, sussurra em segredo o "canto sagrado" - estabelecendo a comunicação entre o divino e o humano - [...] (BAPTISTA, 2011, p. 11, grifo do autor).

É possível afirmar que a poesia dos cantos contribui para que possamos conhecer o registro destas palavras que nos aproximam de um passado indeterminado, porém, sempre presente: o da criação, o da origem. Neste caso, este passado indeterminado está vinculado a uma relação em que o divino e o humano estão interligados pela palavra, pelo saber.

Em Moradas nômades, livro de poemas que compõe a segunda parte de Roça barro$\mathrm{ca}$, a busca pela origem, uma das características do barroco, como bem nos ensina Walter Benjamin, também é matéria de estudo para a poeta/ensaísta. De acordo com as palavras de Baptista: “Os poemas da série 'Moradas nômades', que complementam este Roça barroca, procuram dialogar com a sofisticada trama sonora dos cantos, no umbral em que arcaico e moderno se encontram em cruzamentos híbridos" (BAPTISTA, 2011, p. 13), como afirma no texto que introduz o livro. Nesse diálogo, a autora de Sol sobre nuvens traz à tona o limiar entre o arcaico e o moderno.

Há neles [nos poemas da série "Moradas nômades"] indícios de algumas das inquietações que me movem, como os ritos - em sua vertigem de talhes e detalhes - de passagem, da reprodução e da morte (esta que, historicamente, a arte e a poesia tentam "exorcizar") 
São essas inquietações que estão intrínsecas nesse livro. Segundo a poeta/ensaísta, os 30 poemas que compõem Moradas nômades foram escritos após “[...] algumas viagens, reais e imaginárias, a comunidades Mbyá do Paraná e da região vizinha do Guairá, a fim de conhecer um pouco seu modo de vida, os rituais remanescentes, sua paisagem" (BAPTISTA, 2011, p. 13). Nesse sentido, lê-se nessa narrativa do percurso algo que vai além do simples ato de viajar, lê-se o interesse pela experiência em si, o que resulta na produção de poemas que estão impregnados por essa busca.

[...] Moradas nômades é a procura pela palavra metamorfizada por essas viagens diversas e intemporais - ao texto arcaico e à cosmogonia primeva, à transladação dos sentidos sob paisagens estranhas, ao corpo silencioso e ao ritmo dessa fala em estado de arte que é a poesia - "uma das raras formas de transe relativamente ritualizadas que ainda restam no Ocidente” (BAPTISTA, 2011, p. 15).

Nessa procura pela "palavra metamorfizada por essas viagens diversas e intemporais" reconhecemos que somos instigados a usar um método anacrônico de leitura para colocar em evidência que "[a] concordância dos tempos - quase não - existe" (DIDI-HUBERMAN, 2015, p. 21). Diante desse saber que evidencia a necessidade de se reconhecer a heterogeneidade dos tempos, pode-se afirmar que o anacronismo em Josely Vianna Baptista, que se lê a partir dos vestígios presentes nos poemas, das relações que são sugeridas e, mesmo explícitadas, surge de uma sensibilidade ímpar da poeta aliada à criatividade e à pesquisa.

Vale lembrar que Haroldo de Campos (1969) em A arte no horizonte do provável e outros ensaios, ao dedicar-se à tradução, vai evidenciar a necessidade de se realizar uma tradução crítica e criativa.

O problema da tradução tem um lugar de relêvo neste livro. Não apenas na parte que lhe é nominalmente dedicada, mas permeando muitos dos trabalhos nêle contidos. A tradução aqui - tradução criativa, recriação, - é vista como forma de crítica, e seu exercício manifesta, na prática textual, a visada daquela poética sincrônica, cuja consideração teórica e metodológica encerra êste volume (CAMPOS, 1969, p. 10, grifo do autor).

A tradução em Baptista não será o foco da presente análise, mas, pode-se afirmar que é o resultado de um processo criativo intenso que envolve diversas fontes: teóricas, imagéticas, sonoras, do passado, do presente, do guarani, do espanhol e do português. Por exemplo, já é visível no processo de tradução a existência de pelo menos três tempos. O primeiro, o da língua guarani, o segundo que pertence à revelação/tradução à língua espanhola e esse terceiro tempo, o do desdobramento à língua portuguesa, ou melhor, à língua portuguesa brasileira.

Destaca-se que a tradução é um dos elementos que faz parte do processo de leitura dos ritos dos Mbyá-Guarani e constitui a base para a produção dos poemas que nos são apresentados em Moradas nômades. A análise dos poemas, que é o foco principal deste artigo, evidencia a importância do anacronismo, mas, também de sua necessidade para a sobrevivência da poesia, da Literatura. É interessante salientar que a questão relacionada 
ao processo de colonização realizado pelos portugueses retornará em vários poemas da segunda parte de Roça barroca.

"O anacronismo é necessário" leitura e reflexão sobre três poemas de Josely Vianna Baptista

O anacronismo é necessário, o anacronismo é fecundo, quando o passado se revela insuficiente, até mesmo constitua um obstáculo à sua compreensão.

Geroges Didi-Huberman.

Partindo dos estudos de Georges Didi-Huberman, pode-se afirmar que em Josely Vianna Baptista a convivência de tempos heterogêneos é um dos aspectos que ganha destaque, revelando uma configuração barroco/hermética. Essa configuração barroco/hermética que reconhecemos não tem por objetivo esclarecer, mostrar ou explicitar pedagogicamente; ao contrário, apresenta ao leitor como é possível criar a partir de temporalidades distintas, de vozes múltiplas, nas quais cifrar também pode ser uma maneira usada para explicitar determinado objetivo, ou mesmo, um determinado método.

A partir dessas considerações é sempre importante salientar a necessidade de se ler anacronicamente, de se fazer da leitura um ato criativo e, a partir desse desejo, inicia-se a leitura do primeiro poema de Moradas nômades que é chamado exercício espiritual e é o fio condutor da análise.

\section{exercício espiritual}

Aqui poucas letras bastam, pois tudo é como papel em branco.

Manuel da Nóbrega. Carta 8 (1549)

risco

no portulano

da areia

o roteiro do error

(do latim errore):

viagem sem rumo

e sem fim,

como a dos ascetas

e dos apaixonados,

fadados ao êxtase

e ao naufrágio

(BAPTISTA, 2011, p. 102)

Ao ler-se o título do poema, exercício espiritual, nos deparamos com a intemporalidade, ou seja, a falta de um tempo determinado. Esse tempo indetermidado pode ser, tanto o passado longíncuo, cujo cuidado com a espitirualidade é evidente, quanto o presente complexo, no qual se exige muito mais que paciência diante dos fatos, da vida. No entanto, não há uma marca temporal precisa. Num primeiro momento, pode-se supor que essa 
espiritualidade não estaria ligada a nenhuma religião em especial, e, por isso, o título em si seria uma sorte de proposição e, mesmo, um convite a uma busca, ou melhor, a uma viagem necessária, inapreensível, imaterial, anacrônica.

No entanto, logo após o título do poema há uma epígrafe/poema que faz referência às palavras do sacerdote jesuíta português Manuel da Nóbrega, o que nos leva a compreender que o título do poema nos apresenta outra possibilidade de leitura relacionada à igreja católica, como lemos nos estudos sobre Nóbrega, de João Adolfo Hansen.

Nóbrega subordina a redação de suas cartas às diretivas estabelecidas em 1547 pelo Pe. Polanco e às determinações especificadas nas Constituições da Companhia publicadas por Loyola em 1558. Este afirma que, enquanto observava certas coisas em sua alma e as julgava úteis, parecia-lhe que poderiam ser úteis também aos outros e por isso as escrevia. A prática da escrita deve levar à eleição de uma vida virtuosa em que a purgação do pecado e a iluminação da alma significam a eleição de Deus e a união com Ele. Os Exercícios Espirituais são escritos como o livro de um mestre que se dirige a alguém que os pratica para alcançar esse fim. Nóbrega segue o preceito, escrevendo cartas que inicialmente são lidas por homens da Companhia que, depois de corrigi-las, as transmitem a outros como lição a ser memorizada e repetida (HANSEN, 2010, p. 114, grifo do autor).

De acordo com o texto de Hansen, o uso da escrita estava relacionado aos "exercícios espirituais" recomendados por Loyola, ou seja, pela igreja católica.

A epígrafe, que lemos em forma de poema, é uma adaptação realizada por Josely Vianna Baptista da oitava carta de 1549 do sacerdote português que registra as impressões sobre a terra "descoberta": "aqui poucas letras bastam/ pois tudo é como papel em branco” (BAPTISTA, 2011, p. 102). Os vestígios dessas poucas e ríspidas palavras advindas das referências ao colonizador nos fazem reconhecer o impacto inicial devastador causado na história do Brasil, a partir do período de colonização.

Vale lembrar de outro marco escrito que está relacionado à história do Brasil, a Carta de Pero Vaz de Caminha, cuja data é anterior às palavras de Manoel da Nóbrega, de $1^{\circ}$ de maio de 1500. Segundo Sílvio Castro (2013), com a Carta de Caminha o Brasil é uma nação que tem sua origem marcada pelo signo do escrito. Sílvio Castro em seu texto afirma que "[a] carta de Caminha faz do Brasil possivelmente a única realidade geo-humana moderna possuidora da escritura do próprio ato de nascimento" (CASTRO, 2013, p. 36), no entanto, salienta-se que esse registro de nascimento é feito pelo português/colonizador sobre o Brasil e seus povos.

Josely Vianna Baptista ao inserir a epígrafe referenciando o colonizador nos faz reler mais de uma vez a história, ou seja, mostra-nos a necessidade de realizarmos uma leitura não somente anacrônica, mas crítica. Desse modo, somos convidados, na releitura, a refletir sobre a afirmação "aqui poucas letras bastam" e, ao mesmo tempo, sobre a comparação com o "papel em branco" que faz parte da carta do padre jesuíta.

Pode-se afirmar ainda que, tanto Sílvio Castro, quanto Josely Vianna Baptista nos fazem pensar nessa necessidade contemporânea e, ao mesmo tempo moderna, de compreender o presente com o passado. Por isso, nada é passível de uma leitura definitiva, fechada ou restritiva; há uma constante necessidade de trazer à tona, de relembrar os vários desdobramentos destas "letras" e deste "branco", Josely o faz de maneira exemplar. Na epígrafe, já mencionada, o caráter pejorativo ganha destaque, as palavras do conquistador 
português que "ecoam", reduzem e subtraem a nada a origem: os cantos, os ritos e o modo de vida daqueles que foram encontrados/achados na terra longínqua.

Contrastando com a epígrafe, o poema nos apresenta, simultaneamente, outra leitura que evidencia, por um lado, a fragilidade dos "conquistadores" navegantes e, por outro, o trabalho poético com a linguagem destacando seu caráter duplo e dúbio.

A fragilidade é revelada já no primeiro verso: "o risco".

Esse verso mínimo traz à tona, pelo menos, duas possibilidades de leitura: uma relacionada ao risco enquanto perigo e outra relacionada à rasura. Neste exercício de leitura, optou-se por trabalhar com "o risco" enquanto rasura, ou seja, o risco que borrado, confunde, desvia o olhar da rota, o que resultou(a) no (des)encontro, no engano.

No "exercício espiritual" proposto por Josely Vianna Baptista é possível também vislumbrar além do erro enquanto rasura causada pelo risco no portulano, (carta de navegação marítima medieval), o erro enquanto caminho, roteiro que é registrado no quarto verso do poema: “o roteiro do error" (BAPTISTA, 2011, p. 102). Novamente, outra palavra de duplo sentido: error "(do latim errore):/" (BAPTISTA, 2011, p. 102), tal como explicita o quinto verso do poema, que nos leva até a sua derivação: errar.

E, nesse jogo de decifração/declinação/derivação, errar, por sua vez, nos conduz a outra palavra: "errância", que está vinculada à viagem como também nos sugerem o quinto, o sexto e o sétimo verso do poema, nos quais lemos: “(do latim errore):/ viagem sem rumo/ e sem fim,/ [...]” (BAPTISTA, 2011, p. 102). Essa viagem advinda da errância é comparada pelo eu lírico "a dos astecas e a dos apaixonados,/ fadados ao êxtase e ao naufrágio” (BAPTISTA, 2011, p. 102).

Portanto, o duplo sentido das palavras, o desdobramento das imagens para uma melhor compreensão que se faz presente já no título do livro, Roça barroca, faz com que o poema seja, ao mesmo tempo, o fio condutor de uma reflexão sobre o evento histórico - o achamento/decobrimento do Brasil -, e sobre um presente incerto para o povo indígena e para o brasileiro que diante da história recente se mostra anestesiado e impotente. Talvez, tal reação seja o resultado constituído por esse caráter dúbio, controverso da história, que é algo intrínseco à nação e à literatura brasileira.

Por se tratar de algo intrínseco, o trabalho poético de Baptista não tenta julgar, pelo contrário, nesse caso o fazer poético está aliado ao caráter literário que está vinculado ao histórico. Desse modo, lê-se nos poemas da autora de Sol sobre nuvem a necessidade de apresentar, de usar, de brincar, de desdobrar as palavras, o material essencial e fundamental, tal como reivindicado pelos cantos dos Mbyá-Guarani.

A partir do conhecimento desse jogo com a palavra, voltamo-nos para o segundo poema escolhido de Moradas nômades que é constituído de quatro versos, não possui título e nos é apresentado numa tipografia em caixa alta, como se dessa maneira os poucos versos se expandissem, e ecoassem o grito, e a certeza de que não há presente sem a consciência do passado. Nesse sentido, o anacronismo nos ajuda a compreender que não há o "eu" sem o outro, não há nação constituída por apenas uma única pessoa.

\author{
NENHUM GESTO \\ SEM PASSADO \\ NENHUM ROSTO \\ SEM O OUTRO
}

(BAPTISTA, 2011, p. 109) 
O poema como podemos ler se desdobra sobre si mesmo numa necessidade de registrar, de reafirmar a certeza absoluta que teima em escapulir no vazio do esquecimento: "NENHUM GESTO/ SEM PASSADO" (BAPTISTA, 2011, p. 109). Ao reivindicar o gesto, ou seja, o inapreenssível, o efêmero, Josely Vianna Baptista está enfatizando a existência e a persitência de uma memória temporal que afirma: "NENHUM ROSTO/ SEM OUTRO” (BAPTISTA, 2011, p. 109). E desse modo, recupera a relação primeira, a importância da convivência não somente de tempos heterogêneos, mas de "rostos", de seres díspares. Pode-se pensar que esses seres díspares podem estar relacionados, tanto com o indígena brasileiro e o colonizador português, quanto com a situação atual em que os grupos indígenas continuam, enquanto minoria, sendo alvo do próprio estado brasileiro.

A partir desses dois poemas, que nos introduzem numa trama complexa, somos levados a pensar outras "viagens"/leituras possíveis, por exemplo, reconhecer nas palavras de Baptista uma resposta justa, certeira às palavras de Nóbrega, que servem de referência para o primeiro poema analisado: exercício espiritual. Além disso, há a necessidade de no presente reconhecer e aceitar a importância de um determinado passado que nos acompanha, que nos pertence, assim como, da figura do português, do índio, do outro, que em resumo somos nós mesmos: seres díspares e híbridos que constituem a nação brasileira.

É interessante relembrar que a leitura do mito da origem que Josely Vianna Baptista nos apresenta em sua tradução, que é a primeira parte do livro, possui um caráter complexo e nos direciona a reler o nosso repertório teórico do barroco e do modernismo advindo do pensamento do filósofo Walter Benjamin (1984). Por isso, destaca-se que em Origem do drama barroco alemão, o filósofo alemão vai trabalhar e definir o termo origem como "algo que emerge do vir-a-ser e da extinção".

O termo origem não designa o vir-a ser daquilo que se origina, e sim algo que emerge do vir-a-ser e da extinção. A origem se localiza no fluxo do vir-a-ser como um torvelinho, e arrasta em sua corrente o material produzido pela gênese. O originário não se encontra nunca no mundo dos fatos brutos e manifestos, e seu ritmo só se revela a uma visão dupla, que o reconhece, por um lado, e por isso mesmo completo e inacabado. Em cada fenômeno de origem se determina a forma com a qual a idéia se confronta com o mundo histórico, até que ela atinja a plenitude na totalidade de sua história. A origem, portanto, não se destaca dos fatos, mas se relaciona com sua pré e pós-história (BENJAMIN, 1984, p. 67-68, grifo do autor).

A partir dessa certeza de que a origem advém da emergência de um processo contínuo de vir-a-ser, de recontrução e, paradoxalmente, de extinção, pode-se afirmar que os poemas de Josely Vianna Baptista são o resultado do entendimento desse processo complexo que está relacionado, tanto à origem enquanto um processo de investigação, de pesquisa, quanto com a condição da poesia, da literatura e dos próprios indígenas.

Portanto, os poemas de Baptista além de estarem relacionados à cosmogonia indígena nos levam ora aos estudos de Stéphane Mallarmé (1914) - que foi um dos grandes pensadores sobre a importância da página em branco, da diagramação da página, da necessidade de se ler de diversas maneiras não somente o poema, mas o espaço que o contém -, ora aos poetas concretistas, em especial Augusto e Haroldo de Campos, leitores de Mallarmé, que perfizeram o caminho retomando as investigações dos modernistas brasileiros da década de 1920 .

Josely Vianna Baptista, portanto, refaz, recria, relê esse caminho "concreto" que é, ao mesmo tempo, hermético, rebuscado, barroco, rico, tal como anuncia o título do livro: 
Roça barroca. Seus poemas reafirmam, relembram elegantemente que a ênfase deve ser dada ao humano, à sensibilidade desses corpos feitos de palavras, de desejos e de sonhos, eis a riqueza e o esplendor desta roça.

Pelo viés do desejo se faz necessário recuperar o fôlego, ter consciência não somente das possibilidades da palavra dita, mas do que nos sugere o vestígio, o traço, o risco, o toque e o silêncio da página em branco. É justamente pelo viés do vestígio que podemos realizar a leitura do poema ar, que escolhemos para finalizar a presente leitura.

ar

pois que deuses desejo

nesse deserto bem ime

nso (um cinza-chumbo

nos nubla e a vênus: $\boldsymbol{n}$

uvem de nuvens) e que

erros corrijo nesse en

genho de sins, sem equ

ivoco (um cinza-chumb

o nubla esse cinza: lin

has oblíquas), se nos $s$

em-fins eu meço tão com $f$

im medido (aguça as zí

nias, zum nas glicínia

s: cinza-azulado que a

nula o dia) e se o mun

do segue redondo e im

perfeito nesse moment

o em que tudo está mudo

? (palavras líquidas)

(BAPTISTA, 2011, p. 114, grifo do autor)

Esse poema foi publicado anteriormente em $A r$, outro livro de Josely Vianna Baptista (2007), que se encontra na coletânea chamada Sol sobre nuvem. Nesse caso, é importante salientar que no livro $A r$ o poema em si não possui nome e sua diagramação se encotra diferenciada: ele nos é apresentado justificado, e, por isso, a forma retangular ganha destaque. Do mesmo modo, os demais poemas contidos nesse livro também apresentam uma diagramação que nos remete a alguma figura geométrica. Com relação à tipografia, nas duas versões, $A r \mathrm{e}$ Roça barroca, há o uso da caixa-baixa. Todos esses desdobramentos e detalhes referentes à forma nos convidam a voltar no tempo e a retomar a leitura de Haroldo de Campos (1969), mais especificamente de Haroldo de $A$ arte no horizonte do provável e outros ensaios.

Como viemos destacando, nessas duas versões do poema ar, há pequenas diferenças, são essas diferenças que nos convidam a reler o capítulo "A poética do precário", que é dedicado ao pintor/poeta alemão Kurt Schwitters, como enfatiza o subtítulo: "Kurt Schwitters ou o júbilo do objeto". Neste texto, Haroldo de Campos vai dedicar-se à leitura das collages visuais e verbais de Schwitters sublinhando a importância do uso de materiais diversos em suas composições plásticas, inclusive de materiais que não se esperava encontrar no traba- 
lho de um artista contemporâneo daquela época. Por isso, detemo-nos por um instante nas observações de Haroldo de Campos sobre as Collages visuais e verbais, que conforme pode ser constatado, estavam interligadas pela tipografia, por exemplo.

Há, pois, estreitas zonas de contato e permeabilidade entre as collages visuais de Schwitters e suas collages verbais, além da análoga técnica de expressão implícita nos dois processos. Observando reproduções de seus quadros do gênero, verifica-se que o dado meramente tipográfico sempre está presente nessas composições, metamorfoseado através de découpages, inversões, propositados contrapontos de caracteres gráficos de tipos (gótico, itálico, caixa alta, caixa baixa etc.) e origens diversos, funcionando como um fator que se resolve gestàlticamente no conjunto das partes do quadro, indesligável delas (CAMPOS, 1969, p. 37, grifo do autor).

Pode-se afirmar que em Baptista há traços que advém dessa poética experimental que perntence tanto à vanguarda europeia, quanto à brasileira da qual o próprio Haroldo de Campos é um dos "herdeiros". Ou seja, há explicitamente em Josely Vianna Baptista uma preocupação, tanto com questões visuais, quanto sonoras que são retomadas em seus poemas.

O título ar, por exemplo, destaca-se do restante do poema por ser colocado em negrito. É desse título que o aspecto aerado, leve que encontramos no corpo do poema, emerge, dando ênfase à visualidade; ou seja, é na diagramação centralizada e espalhada do poema que reconhecemos a força a cada verso. Nesse sentido, podemos ler em Josely Vianna Baptista as preocupações que Haroldo de Campos lê em Kurt Schwitters.

Schwitters, pintor, era também o poeta preocupado com a invenção tipográfica, com a desarticulação da palavra, com o aspecto visual dos vocábulos, suas possíveis disposições no horizonte espacial e suas reações e transformações recíprocas quando postos em presença simultânea (CAMPOS, 1969, p. 37).

Ou seja, as preocupações que atravessam a poética de Schwitters, retornam em Baptista por uma via sutil e formal, num primeiro momento, cuja ênfase é colocada na diagramação, na preocupação com a tipografia e com a desarticulação de algumas palavras, o que vai resultar num trabalho com a sintaxe e com a sonoridade, que também Campos destaca em seu texto com relação à poética do artista alemão.

De seu trato de humildade com o material, de sua preocupação minuciosa e paciente com a textura do objeto verbal despido de categoria "literária" prèviamente convencionada, Schwitters é conduzido irresistivelmente à pesquisa dos próprios elementos fundamentais da expressão poétca, e, visando à "coisa em si" dessa expressão, só se detém em sua espeleologia lingüítica no próprio som, no fonema, na sílaba, nos radicais do idioma: não de um certo e determinado idioma, mas de um substrato vocal que poderia informar qualquer lingua. [...] (CAMPOS, 1969, p. 42).

Em ar, pode-se afirmar que a experiência sonora, por exemplo, é um dos aspectos que retornam retrabalhados, enquanto vestígio dessa primeira vanguarda da qual Schwitters faz parte com suas experiências visuais e sonoras, tal como Campos faz questão de destacar a partir de seus comentários sobre URSONATE, experiência sonora realizada pelo artista alemão em 1932. 
URSONATE, também designada como SONATE IN URLAUTEN [...]. São blocos de som, organizados por fatôres de timbre e duração, que, despidos da investidura léxica, traçam uma espécie de pré-história do auditivo, revelando a infra-estrutura fonética adormecida sob as cunhagens gastas tanto do idioma de comunicação utilitária, como do de convenção "belartística"; possibilitam um retôrno às matrizes do material poético, um puro júbilo do objeto verbal resgatado à grilheta dos hábitos semânticos e morfológicos e ativado por novos oxigênios (CAMPOS, 1969, p. 43-44).

Ao contrário do que ocorre nas investigações sonoras de Kurt Schwitters (1932) realizadas em URSONATE, em Josely Vianna Baptista a experiência sonora não é tão radical. A palavra, o poema, dependendo da maneira de ler escolhida pelo leitor, mantém seu sentido, não se atém apenas em investigações sonoras. No entanto, é importante salientar que Baptista mantém um interesse em desarticular as palavras, escandindo-as de uma maneira singular que faz com que o leitor pare, releia, reelabore a sua maneira de ler o poema. Diante dessa exigência/experiência do poema, pode-se afirmar que as preocupações que estavam em Schwitters retornam enquanto eco, sussurro, ar, como nos seguintes versos que iniciam e terminam como se tivessem sido interrompidos antecipadamente, restando apenas a sugestão em forma de certa gagueira, de um som que também é ruído:

Portanto, no poema ar há várias questões que podem ser analisadas além da sua relação com as experiências sonoroas e visuais já destadacas; há, por exemplo, o dualismo presente na retomada da relação entre o sagrado, o divino, próprios dos deuses e o desejo, próprio do ser humano. Nesse sentido, o desejo e a sensualidade que vêm à tona, ganham espaço, mostram-se integrantes do "deserto bem ime/nso" (BAPTISTA, 2011, p. 114).

Essa presença de tempos distintos, como já destacamos anteriormente, é evidente nesse poema e nos é revelada já no primeiro verso "pois que deuses desejo/" (BAPTISTA, 2011 , p. 114). Eis a retomada no presente de um pretérito marcado pela mitologia, que vem à tona pela menção da deusa do amor Vênus, tal como lemos no quarto verso: “/ nos nubla e a vênus: n/" (BAPTISTA, 2011, p. 114). Esse desejo pelo mitológico, pelo 
inapreeensível que está intrínseco no poema e se revela no jogo temporal, no qual ao invés da mescla, vem à tona o presente entrecortado pelas palavras de um eu lírico que se apresenta em primeira pessoa, que escande, corta, desmonta palavras e, ao mesmo tempo, rabisca outras, interrompe o fluxo, o fôlego da leitura e nos devolve a imagem cinza-azulada-nublada de uma terra "im/ perfeita" (BAPTISTA, 2011, p. 114).

Desse modo, ao nos determos nesse poema constatamos a importância do reconhecimento dessas temporalidades distintas, que perpassam a vanguarda europeia e a brasileira, e se apresentam enquanto traços que nos fazem rever as certezas e pensar nas possibilidades que o poema e o fazer poético nos apontam.

É necessário frisar que além de nos colocar questões morfológicas e sintáticas, Josely Vianna Baptista nos instiga a retomar o poema pelo viés da subjetividade que está no desejo pelo imaterial, pelo inapreensível, que está nas formas e nas palavras ditas e, mesmo, naquelas que ficam apenas subentendidas. Por exemplo, a palavra erro, que já foi foco de comentários da leitura do primeiro poema, exercício espiritual, retorna neste poema.

Naquele primeiro poema, a palavra erro nos remetia à errância, à viagem, à certeza do deslocamento. Mas, o erro que retorna em ar já não é mais o mesmo. É o da dúvida, da ruptura que está aliado a essa escanção abrupta que interrompe e dificulta a leitura: “/[...] e que/ erros corrijo nesse en/ genho de sins, sem equ/ ívoco (um cinza-chumb/ o nubla esse cinza: lin/ has obliquas), [...]" (BAPTISTA, 2011, p. 114). A dúvida com relação a quais erros corrigir se instaura, e outro elemento vem à tona ao longo do poema: uma imagem-palimpsesto construída através da sobreposição, como pode ser verificado no terceiro, quarto, oitavo, nono, décimo quarto e décimo quinto versos, respectivamente: “[...] (um cinza-chumbo/ nos nubla [...])/ [...] [ [...] (um cinza-chumb/ o nubla esse cinza: lin/ [...]/ [...] s: cinza-azulado que a/ nula o dia) [...]" (BAPTISTA, 2011, p. 114).

A imagem que se constrói no poema é a de um céu. Esse céu vem à tona radiante a partir de camadas formadas por "linhas oblíquas" que nos sugerem a sua presença, mesmo que em nenhum verso a palavra "céu” seja dita, mencionada. E, eis que nos voltamos para a terra/mundo, esfera imperfeita que nos leva ao último canto dos guarani: "A primeira terra". Nesse canto, nos é descrito como o deus supremo cria a terra a partir da ponta de seu bastão e como finaliza o processo "estabelecendo a comunicação entre o divino e o humano" (BAPTISTA, 2011, p. 11).

É desse processo imperfeito e rebuscado de formação e comunicação que emerge essa poesia "original", que sempre retorna. O papel em branco solicitado pelo colonizador português no poema exercício espiritual é transformado, retrabalhado e nos é apresentado no poema ar, como céu. O céu e seus diversos tons de cinzas e azuis que é desenhado com palavras que se dobram e desdobram como a busca pela resposta justa. Mas a única certeza encontrada é aquela relacionada ao mundo e às palavras: “... o mu/ ndo segue redondo e im/ perfeito" e as "palavras líquidas" (BAPTISTA, 2011, p. 114, grifo do autor).

\section{Considerações finais}

Para finalizar, pode-se afirmar que Josely Vianna Baptista com seu pequeno gesto político/poético procura nos mostrar como é possível aproximar nossa poesia, "a ocidental", da beleza cifrada que se lê na poesia ameríndia. E, pelo viés da palavra cifrada, reconhecemos que a contemporaneidade continua sendo o tempo da busca pela convivência em harmonia com o outro, é o tempo de uma constante busca pela certeza que sempre nos es- 
capa. Nesse sentido, a única certeza que se tem no presente é a possibilidade de se rearmar a discusão em torno da poesia, em especial, dessa poesia barroco/hermética, que em sua erudição, dá vislumbre e visibilidade às belas e indestrutíveis "palavras azuis celestes". Pelo viés das "palavras azuis celestes", vale sempre lembrar que o que nos distingue dos animais é a linguagem. Uma linguagem rebuscada, rica, que foi/é tão cara ao Barroco, faz-se ainda presente em Baptista conforme foi apresentado nessa leitura.

O retorno do Barroco se dá, nos poemas que foram analisados, pelo viés formal, pelo fato de estarmos diante de poemas que nos fazem reorganizar momentos históricos da nossa poesia em diálogo com outros tempos, por exemplo, com o das varguardas, brasileira e europeia, e todo seu caráter experimental e erudito. O Barroco também se faz presente pela necessidade que lemos em Baptista de apresentar a riqueza de tempos distintos atravessados pelos sentidos, que fazem da poesia um ato político, no qual se reivindica a riqueza, o extraordinário, contidos na palavra e a certeza de que é pela aceitação das diferenças, que estão nesse "eu” que é feito de muitos outros, que é possível a sobrevivência da poesia, do ser humano.

É na retomada dos vestígios desse passado que é reatualizado a cada gesto, a cada movimento, a cada palavra que se desloca e que se desdobra, que temos a responsabilidade de apresentar a grandiosidade, a imensidão do poema e da poesia em tempos tão difíceis como o nosso presente. Lemos em Baptista um convite a rearmar a leitura, a apreciar e a aceitar as diferenças a partir de uma escritura sutil e rebuscada, erudita e sensível, a partir da qual somos sempre confrontados e questionados.

Por isso, é importante salientar que a poesia de Josely Vianna Baptista ultrapassa o contraste, a dubiedade do Barroco tradicional, ela troca o branco e preto pelo palimpsesto, pela sobreposição de cinzas e azuis, mostrando-nos que a poesia do presente pode ser simples, mas nunca simplória. Que a poesia é, e sempre foi, um caminho possível para pensar questões complexas que atravessam e reconstroem o presente, a linguagem e o poético com o político.

\section{Referências}

AGAMBEN, G. O que é um dispositivo. Outra Travessia 5. Ilha de Santa Catarina, 2. Semestre. 2005. Trad. Nilcéia Valdati.

BAPTISTA, J. V. Roça barroca. São Paulo: Cosac Naify, 2011. . Sol sobre nuvem. São Paulo: Perspectiva, 2007.

BARBOSA, L. G. Arquivo arcaico. Rascunho. Jornal de literatura do Brasil. Edição 148. Disponível em: <http://rascunho.com.br/arquivo-arcaico/>. Acesso em: jul. 2017. BENJAMIN, W. Origem do drama barroco alemão. São Paulo: Brasiliense, 1984. CADOGAN, L. Ayvu rapyta: Textos míticos de los Mbyá-Guarani del Guairá. 1992. Disponível em: < http:/www.portalguarani.com/793_leon_cadogan/13473_ayvu_rapyta_textos_miticos_de_los_mbya_guarani_del_guaira_obra_de_leon_cadogan_html $>$. Acesso em: 01 maio 2017.

CAMPOS, H. A arte no horizonte do provável e outros ensaios. São Paulo: Editora perspectiva, 1969.

CASTRO, S. (Org.). A carta de Pero Vaz de Caminha. O descobrimento do Brasil. São Paulo: L\&PM, 2013. 
DIDI-HUBERMAN, G. Diante do tempo. História da arte e anacronismo das imagens. Belo Horizonte: Editora UFMG, 2015. Trad. Vera Casa Nova, Márcia Arbex.

HANSEN, J. A. Manuel da Nóbrega. Recife: Fundação Joaquim Nabuco, Editora Massangana, 2010.

LAPASSADE, G. (1987). Les états modifiés de conscience. In: MALLARMÉ, S. Un coup de dés jamais n'abolira l'hasard. La nouvelle reveu française. Paris: PUF, 1914. ROA BASTOS, A. Catecismo da beleza. In: BAPTISTA, J. V. Roça barroca. São Paulo: Cosac Naify, 2011.

Recebido em: 08/05/2018 Aceito em: 07/07/2018 